\title{
In situ measurement-based partitioning behavior of perfluoroalkyl acids in the atmosphere
}

\author{
Seung-Kyu Kim ${ }^{1,2^{\dagger}}$, Donghao $\mathrm{Li}^{3}$, Kurunthachalam Kannan ${ }^{4}$ \\ ${ }^{1}$ Department of Marine Science, College of Natural Sciences, Incheon National University, Incheon 22012, Republic of Korea \\ ${ }^{2}$ Research Institute of Basic Sciences, Incheon National University, Incheon 22012, Republic of Korea \\ ${ }^{3}$ Key Laboratory of Nature Resource of the Changbai Mountain and Functional Molecular, Yanbian Univeristy, Ministry of Education, Park Road 977, \\ Yanji City 13302, China \\ ${ }^{4}$ Wadsworth Center, New York State Department of Health, and Department of Environmental Health Sciences, School of Public Health, State \\ University of New York at Albany, New York 12201, United States
}

\begin{abstract}
Environmental fate of ionizable organic pollutants such as perfluoroalkyl acids (PFAAs) are of increasing interest but has not been well understood because of uncertain values for parameters related with atmospheric interphase partitioning behavior. In the present study, not only the values for air-water partition coefficient $\left(\mathrm{K}_{\mathrm{AW}}\right)$ and dissociation constant $(\mathrm{pKa})$ of PFAAs were induced by adjusting to in situ measurements of air-water distribution coefficient between vapor phase and rainwater but also gas-particle partition coefficients were also estimated using three-phase partitioning model of ionizable organic pollutants, in situ measurements of PFAAs in aerosol and air vapor phase, and obtained parameter values. The pKa values of PFAAs we obtained were close to the minimum values suggested in literature except for perfluorooctane sulfonic acids, and COSMOtherm-modeled $K_{A W}$ values were assessed to more appropriate among suggested values. When applying parameter values we obtained, it was predicted that air particle-associated fate and transport of PFAAs could be negligible and PFAAs could distribute ubiquitously along the transection from urban to rural region by $\mathrm{pH}$-dependent phase transfer in air. Our study is expected to have some implications in prediction of the environmental redistribution of other ionizable organic compounds.
\end{abstract}

Keywords: Acidity, Fog, Inter-phase distribution, Ioniable organic pollutants, PFAAs, pKa

\section{Introduction}

Per- and polyfluoroalkyl substances (PFASs) are global pollutants, which were listed as persistent organic pollutants (POPs) by the Stockholm Convention [1]. Once released into the environment, organic pollutants experience various phase-partitioning between solid phases (e.g., soil, sediment, air particle, and biota, etc.), water phase, and air vapor phase. Particularly, atmospheric fate and transport plays an important role to their redistribution among environmental compartments and long-range transport, as frequently mentioned as 'grasshopper effect' [2].

In atmosphere, the partitioning behavior of neutral PFASs such as fluorotelomer alcohols and perfluooctane sulfonamidoethanols have been predicted comparatively easily using their two-phase partitioning coefficient (e.g., gas-particle partition) because of their less soluble property [3, 4]. Acid PFAS group (perfluoroalkyl acids (PFAAs)) exist as the free acid form (i.e., neutral species) and their conjugate base form (i.e., ionic species) as shown in perfluoroalkyl carboxylic acids/carboxylates (PFCAs) or perfluoroalkane sulfonic acids/sulfonates (PFSAs) [5]. Differently from neutral PFASs, the environmental fate of PFAAs has been less known and is still in debate, which is related with the presence of both neutral and ionic species and the significant uncertainties in their physicochemical properties such as dissociation constant (i.e., $\mathrm{pK}_{\mathrm{a}}$ ) and air-water partition coefficient $\left(\mathrm{K}_{\mathrm{AW}}\right)$ [6-8].

PFAAs are dissociated into their ionic species when they meet the aqueous phase and in the typical aquatic $\mathrm{pH}$ conditions are known to exist as mostly ionic species, which is difficult to be volatilized [8]. Therefore, their airborne transport mechanism has been ignored for long time because PFAAs were considered to
This is an Open Access article distributed under the terms of the Creative Commons Attribution Non-Commercial License (http://creativecommons.org/licenses/by-nc/3.0/) which permits unrestricted non-commercial use, distribution, and reproduction in any medium, provided the original work is properly cited.

Copyright (C) 2020 Korean Society of Environmental Engineers
Received March 30, 2019 Accepted April 23, 2019

${ }^{\dagger}$ Corresponding author

Email: skkim@incheon.ac.kr

Tel: +82-32-835-8862 Fax: +82-32-835-0806

ORCID: 0000-0002-1602-3288 
be rarely present in the atmosphere. Their presence observed in rain water, had not been well explained, was later attributed to the transformation of volatile and less soluble precursors (i.e., neutral PFASs) to soluble PFCAs and PFSAs [6, 7]. In our previous study [8], however these ionizable organic pollutants (i.e., PFCAs and PFSAs) were measured in rain samples as well as air samples such as gas- and particle-phases. Furthermore, gradually decreasing distribution pattern from source (urban) area to non-source (rural) area could not be explained by previous precursor-based transport mechanism [6, 7, 9]. Furthermore, elevated occurrence of PFAAs in surface runoff samples implicated that their redistribution among environmental compartments through air-water (or surface) partition might occur significantly $[8,10]$. Since then, several studies also confirmed the presence of PFAAs in atmospheric compartments including aerosol and air vapor phases [11-13]. As a possible mechanism to account for the occurrence of PFAAs in atmosphere, McMurdo et al. [14] proposed "PFAAs enrichment in aerosol by the splashing of surface water and occurrence of gaseous PFAAs by gradual volatilization of water molecules". Thus, the redistribution of PFAAs through atmospheric transport can be more significant in coastal region or urban area with large human and/or industrial activities and large water body, considering that 1) surface water can be easily splashed into air by strong wind and wave, 2) their ionic species can exist abundantly in seawater (particularly, they can highly accumulate in the surface microlayer) [15], and additionally 3) fog can frequently be formed owing to difference of air-water temperature [16]. By redistribution process in the environment, human being may be exposed to these toxic substances through multiple pathways via drinking, food intake, dermal contact and inhalation [17, 18].

Differently from insoluble and neutral POPs, ionizable organic pollutants such as PFAAs distribute among three phases in atmosphere, including particle phase, vapor phase, and aqueous phase $[11,12,14]$. The redistribution of PFAAs among environmental compartments thus may be significantly influenced by the atmospheric three-phase distribution (or partitioning) behavior which strongly depends on the extent of their dissociation [19]. It is thus indispensable to use accurate values for the parameters related with their dissociation such as $\mathrm{pK}_{\mathrm{a}}$, solution $\mathrm{pH}$, and water volume (e.g., relative humidity) in predicting their atmospheric interphase-partitioning behavior. Until recently, wide ranges of $\mathrm{pK}_{\mathrm{a}}$ and $K_{A W}(\sim 10,000$ times difference between minimum and maximum values) have been suggested (see references described in section 3.2). Uncertain parameter values could be significant factors amplifying the uncertainty in the prediction of atmospheric fate and transport, including air-water distribution coefficient $\left(D_{A W}\right)$, gas-particle partition coefficient $\left(\mathrm{K}_{\mathrm{P}}^{\prime}\right)$ dry/wet deposition, and long-range transport potential [12, 20-22].

The present work aimed 1) to estimate the reliable $\mathrm{pK}_{\mathrm{a}}$ and $\mathrm{K}_{\mathrm{AW}}$ values by adjusting $\mathrm{t}$ to in situ $\mathrm{D}_{\mathrm{AW}}$ measured between air vapor phase and rainwater, 2) to induce $K_{P}$ using in situ measured gas-aerosol partition coefficient $\left(K_{P}^{\prime}\right)$ and adjusted values for $K_{A W}$ and $\mathrm{pK}_{\mathrm{a}}$, and finally 3 ) to predict their occurrence in each phase of atmosphere with variation of meteorological condition.

\section{Materials and Methods}

\subsection{Sampling and Chemical Analysis}

The present study focuses on the interpretation of the partition behavior of ionizable organic compounds such as PFAAs, based on our previous measurements [8]. Thus, only brief information on sampling of atmospheric phases was described here and the more details of sampling and chemical analysis were presented elsewhere [8].

In brief, three atmospheric phases (air gaseous and particulate phases, and rainwater) were collected at the Washington Park in downtown Albany, New York with a population of 96,000. The Washington Park (ca., total area of $360,000 \mathrm{~m}^{2}$ ) lake has a water surface area of $2 \times 10^{5} \mathrm{~m}^{2}$ and an average depth of $3 \mathrm{~m}$ (so, lake water volume $=\sim 70,000 \mathrm{~m}^{3}$ ). All of the atmospheric samples were collected on the roof of a lake house building about ten meters above the surface of lake, located at the Washington Park. Gaseous and particulate phase of air $(n=8)$ were collected from May to July, 2007 using a high-volume air sampler. PUF/XAD-2/PUF sandwich (Supelco, Bellefonte, PA) and quartz fiber filter (QMA, Whatman) were used to collect gaseous and particulate phases, respectively. The collected air samples were kept at $4^{\circ} \mathrm{C}$ with prior to analysis and were extracted with no desiccation in a few days after sampling. Desiccation of QMA can cause a removal of water phase on the filter and sequential volatilization of neutral species in water phase. Thus, no desiccation of QMA sample can prevent the potential loss of neutral species. Rainwater samples $(n=3)$ of $\sim 200 \mathrm{~mL}$ were collected in methanol-rinsed polypropylene bottles equipped with a funnel next to air sampler.

\subsection{Partition Behavior of PFAAs Among Atmospheric Compartments}

Once organic acids such as PFCAs and PFSAs are dissociated in aqueous phase, the acids (hereafter, neutral species) are in equilibrium with their conjugate base (hereafter, ionic species) as shown in an example of perfluorooctanoic acids (PFOA) Eq. (1-1) and (1-2). Such a dissolution yields the presence of both neutral species $\left(\mathrm{C}_{7} \mathrm{~F}_{15} \mathrm{COOH}\right)$ and ionic species $\left(\mathrm{C}_{7} \mathrm{~F}_{15} \mathrm{COO}^{-}\right)$that strongly depends on their dissolution constants $\left(\mathrm{pK}_{\mathrm{a}}\right)$ and $\mathrm{pH}$ of aqueous phase as shown in Eq. (1)-(2).

$$
\begin{gathered}
{\left[C_{7} F_{15} \mathrm{COOH}\right]=\left[H^{+}\right]\left[C_{7} F_{15} \mathrm{COO}^{-}\right] \text {in aqueous phase (1-1) }} \\
\frac{\left[C_{7} F_{15} \mathrm{COO}^{-}\right]}{\left[C_{7} F_{15} \mathrm{COOH}\right]}=10^{(p H-p K a)}
\end{gathered}
$$

Typically atmosphere consists of aerosol phase (air particle phase and water droplet phase) and air vapor phase. As POPs, well known as representative neutral organic compounds, are rarely water soluble, their $K_{P}$ can be well modeled using a two-phase (i.e., air vapor-particle) sorption equation where a water droplet phase of aerosol can be ignored [23]. However, PFAAs can be present in all of three phases and then their speciation in vapor and water phases should be quantified in advance, being expressed by $D_{A W}$ 
(dimensionless) incorporating both neutral and ionic species as shown in Eq. (2).

$$
D_{A W}=\frac{K_{A W}}{1+10^{(p H-p K a)}}
$$

where $\mathrm{D}_{\mathrm{Aw}}$ indicates the ratio of the concentration of neutral species in air vapor to the total concentration of neutral and ionic species in aqueous phase at the given solution $\mathrm{pH}$. The $\mathrm{K}_{\mathrm{AW}}$ is the air-water partition coefficient of neutral species $\left(\mathrm{m}^{3}{ }_{\text {water }} / \mathrm{m}^{3}\right.$ airvapor $)$.

Gas-particle partitioning can be quantified on basis of the measured concentrations as expressed in Eq. (3), in which the term of $C_{P}{ }^{\prime}$ (unit; $\mathrm{mol} / \mathrm{m}^{3}$ ) indicates the measured concentrations of all PFAA species present on aerosol that is a sum of neutral species adsorbed on particle, neutral species in water phase, and ionic species in water phase, and the denominator $\left(C_{A} ; \mathrm{mol} / \mathrm{m}^{3}\right)$ indicates the measured concentration of neutral PFAA species present in vapor phase.

$$
K_{P}^{\prime}=\frac{\left(C_{P}{ }^{\prime} / T S P\right)}{C_{A}}
$$

where TSP is the mass concentration of total suspended particulate matter in air $\left(\mu \mathrm{g} / \mathrm{m}^{3}\right.$ air $)$. Although $K_{P}{ }^{\prime}$ based on the measured $C_{P}{ }^{\prime}$ and $C_{A}$ indicates TSP-normalized partition coefficient, PFAAs on aerosol $\left(C_{P}{ }^{\prime}\right)$ include both neutral and ionic species in aerosol (i.e., particle-phase and water-phase) and then can vary with the volume of water phase (i.e., relative humidity). Therefore, it is necessary to convert $K_{P}{ }^{\prime}$ to the gas-particle partition coefficient independent on the volume of water-phase $\left(K_{P}\right)$, which is known to be a conventional gas-particle partition coefficient for insoluble organic pollutants.

Contrary to $K_{P}{ }^{\prime}$, the $K_{P}$ is defined as the partitioning coefficient between air vapor and particle for the neutral species alone. Meanwhile, it is difficult to isolate and measure solely neutral species adsorbed on particle-phase because both neutral and ionic species exist together in aerosol consisting of particle and water-phase. Furthermore neutral species can be lost via evaporation when filter paper is desiccated. Alternatively, the $K_{P}^{\prime}$ can be converted to $K_{P}$ by multiplied by the fraction of particle-adsorbed neutral species to total species in aerosol ( $\left.\alpha_{\text {neutral on particle }}{ }^{\prime}\right)$ as given by the following expression:

$$
\begin{gathered}
K_{P}\left(=\frac{C_{P} / \text { TSP }}{C_{A}}\right)=K_{P}{ }^{\prime} \alpha_{\text {neutral on particle }}{ }^{\prime} \\
\alpha_{\text {neutral on particle }}{ }^{\prime}=\frac{C_{\text {neutral on particle }}\left(=C_{P}\right)}{C_{\text {total_aerosol }}\left(=C_{P}{ }^{\prime}\right)} \\
=\frac{C_{\text {neutral on particle }}}{C_{\text {neutral on particle }}+C_{\text {neutral in water }}+C_{\text {ionicin water }}}
\end{gathered}
$$

Likewise, the fractions of neutral species adsorbed on the air particle $\left(\alpha_{\text {neutral on particle }}\right)$, neutral species dissolved in water phase $\left(\alpha_{\text {neutral in water }}\right)$, ionic species in water phase $\left(\alpha_{\text {ionicin water }}\right)$, and neutral species in air vapor $\left(\alpha_{\text {neutral in air vapor }}\right)$ in total air which consist of gaseous, particulate, and water phases can be calculated as follows:

$$
\begin{aligned}
& \alpha_{\text {neutral on particle }}=\frac{C_{\text {neutral on particle }} T S P}{\left(C_{\text {neutral on particle }} T S P+C_{\text {neutral in water }} V_{W_{-} r H}+C_{\text {ionicin water }} V_{W_{-} r H}\right)+C_{\text {neutral in air vapor }} V_{\text {air vapor }}} \\
& \alpha_{\text {free acid in water drolet }}=\frac{C_{\text {neutral in water }} V_{W_{-} r H}}{\left(C_{\text {neutral on particle }} T S P+C_{\text {neutral in water }} V_{W_{-} r H}+C_{\text {ionicin water }} V_{W_{-} r H}\right)+C_{\text {neutral in air vapor }} V_{\text {air vapor }}} \\
& \alpha_{\text {anion in water drolet }}=\frac{C_{\text {ionicin water }} V_{W_{-} r H}}{\left(C_{\text {neutral on particle }} T S P+C_{\text {neutral in water }} V_{W_{-} r H}+C_{\text {ionicin water }} V_{W_{-} r H}\right)+C_{\text {neutral in air vapor }} V_{\text {air vapor }}} \\
& \alpha_{\text {free acid in air vaopr }}=\frac{C_{\text {neutral in air vapor }} V_{\text {air vapor }}}{\left(C_{\text {neutral on particle }} T S P+C_{\text {neutral in water }} V_{W_{-} r H}+C_{\text {ionic in water }} V_{W_{-} r H}\right)+C_{\text {neutral in air vapor }} V_{\text {air vapor }}}
\end{aligned}
$$

where $C_{\text {neutral on particle }}, C_{\text {neutral in water }}, C_{\text {ionicinwater }}, \quad$ and $C_{\text {neutral in air vapor }}$ are the concentrations of neutral species adsorbed

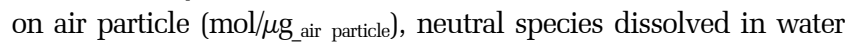
phase of air ( $\mathrm{mol} / \mathrm{m}^{3}$ water phase of air), ionic species dissolved in water phase of air ( $\mathrm{mol} / \mathrm{m}^{3}$ _water phase of air), and neutral species in air vapor phase ( $\mathrm{mol} / \mathrm{m}_{\text {_air vapor }}^{3}$, respectively. The $\mathrm{V}_{\mathrm{W}_{-} \mathrm{rH}}$, and $\mathrm{V}_{\text {air vapor }}$ indicate the volume of water phase $\left(\mathrm{m}^{3}{ }_{-}\right.$water droplet $/ \mathrm{m}^{3}$ air $)$ at a given relative humidity $(\mathrm{rH})$ and the volume of air vapor phase $\left(\mathrm{m}^{3}\right.$ _air vapor $/ \mathrm{m}^{3}$ air $)$ in an unit air volume $\left(\mathrm{V}_{\text {air }} ; 1 \mathrm{~m}_{\text {_air }}^{3}\right)$, respectively. Strictly speaking total air volume is the sum of the volumes of air vapor $\left(\mathrm{V}_{\text {air vapor }}\right)$, air water $\left(\mathrm{V}_{\mathrm{W}_{-} \mathrm{rH}}\right)$, and air particle $\left(\mathrm{V}_{\text {air }}\right.$ particle), but practically $V_{\text {air }}\left(=1 \mathrm{~m}^{3}\right) \cong v_{\text {air vapor }}$ because the faction of $\mathrm{V}_{\mathrm{W}_{-} \mathrm{rH}}$ and $\mathrm{V}_{\text {air particle }}$ 
account for just $10^{-5}$ (at relative humidity $=50 \%$ ) and $10^{-11}$ (at a typical TSP $=60 \mu \mathrm{g} / \mathrm{m}^{3}$ ), respectively. Dividing Eq. (5-1) to (5-4) by $C_{\text {neutral in water }} V_{W_{-} r H}$ yields

$$
\begin{aligned}
& \alpha_{\text {neutral on particle }}= \\
& K_{P W}\left(\frac{T S P}{V_{W_{-} r H}}\right) \\
& K_{P W}\left(\frac{T S P}{V_{W_{-} r H}}\right)+1+10^{(p H-p K a)}+K_{A W}\left(\frac{V_{a i r}}{V_{W_{-} r H}}\right) \\
& \alpha_{\text {neutral in water drolet }}= \\
& \frac{1}{K_{P W}\left(\frac{T S P}{V_{W_{-} r H}}\right)+1+10^{(p H-p K a)}+K_{A W}\left(\frac{V_{a i r}}{V_{W_{-} r H}}\right)} \\
& \alpha_{\text {ionic in water drolet }}= \\
& \frac{10^{(p H-p K a)}}{K_{P W}\left(\frac{T S P}{V_{W_{-} r H}}\right)+1+10^{(p H-p K a)}+K_{A W}\left(\frac{V_{a i r}}{V_{W_{-} r H}}\right)} \\
& \alpha_{\text {neural in air vaopr }}= \\
& \frac{K_{A W}\left(\frac{V_{a i r}}{V_{W_{-} r H}}\right)}{K_{P W}\left(\frac{T S P}{V_{W_{-} r H}}\right)+1+10^{(p H-p K a)}+K_{A W}\left(\frac{V_{a i r}}{V_{W_{-} r H}}\right)}
\end{aligned}
$$

where $K_{P W}$ is the particle-water partition coefficient (unit; $\mathrm{m}^{3} / \mu \mathrm{g}$ ) which is frequently used to explain partitioning between sediment and water in aquatic system. The $K_{P W}$ is associated with organic carbon-water partition coefficient $\left(\mathrm{K}_{\mathrm{OC}}\right)$ or octanol-water partition coefficient (Kow) as shown in Eq. (7).

$$
K_{P W}=\beta f_{O C} K_{O C}=\beta f_{O C}\left(0.41 K_{O W}\right)
$$

where $\beta$ is a correction factor $\left(=10^{12}\right)$ to match the units of $\mathrm{K}_{\mathrm{PW}}$ $\left(\mathrm{m}^{3} / \mu \mathrm{g}\right)$ and $\mathrm{K}_{\mathrm{OC}}(\mathrm{L} / \mathrm{kg})$. The $f_{O C}$ is the fraction of organic carbon in particle (dimensionless) and 0.2 was used for $\mathrm{f}_{\mathrm{OC}}$ of air particle $[24,25]$.

Again, the fractions of individual-phase of neutral and ionic species in aerosol are induced from Eq. (6-1) to (6-4) and can be obtained as follows:

$\alpha_{\text {neutral on particle }}{ }^{\prime}=\frac{\beta f_{O C} K_{O C}\left(\frac{T S P}{V_{W_{-} r H}}\right)}{\beta f_{O C} K_{O C}\left(\frac{T S P}{V_{W_{-} r H}}\right)+1+10^{(p H-p K a)}}$

$\alpha_{\text {neutral on water droplet }}=\frac{1}{\beta f_{O C} K_{O C}\left(\frac{T S P}{V_{W_{-} r H}}\right)+1+10^{(p H-p K a)}}$

$\alpha_{\text {neutral on water droplet }}{ }^{\prime}=\frac{10^{(p H-p K a)}}{\beta f_{O C} K_{O C}\left(\frac{T S P}{V_{W_{-} r H}}\right)+1+10^{(p H-p K a)}}$

where we used the relationship of $K_{O C}=0.41 K_{O W}[26]$.

\section{Results and Discussion}

\subsection{PFAAs Measured in Atmospheric Compartments}

Mean concentrations of PFAAs used for atmospheric partitioning of this study were listed in Table 1. Of six PFCAs, PFOA was the most prevalent compound which was detected in all samples

\begin{tabular}{|c|c|c|c|c|c|c|c|c|}
\hline \multirow[b]{2}{*}{ PFHpA } & \multicolumn{2}{|c|}{ Air vapor $\left(\mathrm{mol} / \mathrm{m}^{3}\right)$} & \multicolumn{3}{|c|}{ Air particle $(\mathrm{mol} / \mu \mathrm{g})$} & \multicolumn{3}{|c|}{ Rain water $\left(\mathrm{mol} / \mathrm{m}^{3}\right)$} \\
\hline & $7.2 \mathrm{E}-16$ & $\pm \quad 3.1 \mathrm{E}-16$ & $1.5 \mathrm{E}-17$ & \pm & 8.6E-18 & 1.5E-09 & \pm & $9.1 \mathrm{E}-11$ \\
\hline PFOA & $7.6 \mathrm{E}-15$ & $\pm \quad 3.8 \mathrm{E}-15$ & $6.6 \mathrm{E}-17$ & \pm & $2.7 \mathrm{E}-17$ & 6.7E-09 & \pm & $3.9 \mathrm{E}-10$ \\
\hline PFNA & $4.6 \mathrm{E}-16$ & $\pm 1.0 \mathrm{E}-16$ & $5.0 \mathrm{E}-18$ & \pm & $2.7 \mathrm{E}-18$ & 3.0E-09 & \pm & $4.8 \mathrm{E}-10$ \\
\hline PFDA & $1.2 \mathrm{E}-15$ & $\pm \quad 8.7 \mathrm{E}-16$ & 8.2E-18 & \pm & 6.5E-18 & 2.2E-09 & \pm & $3.4 \mathrm{E}-12$ \\
\hline PFUnDA & & - & & - & & 1.0E-09 & \pm & $1.7 \mathrm{E}-10$ \\
\hline PFDoDA & $4.4 \mathrm{E}-16$ & $\pm 1.4 \mathrm{E}-16$ & $1.0 \mathrm{E}-17$ & \pm & 7.0E-18 & $9.3 \mathrm{E}-10$ & \pm & $0.0 \mathrm{E}+00$ \\
\hline PFHS & 7.7E-16 & $\pm \quad 2.5 \mathrm{E}-16$ & & - & & & - & \\
\hline PFOS & $3.4 \mathrm{E}-15$ & $\pm 1.4 \mathrm{E}-15$ & $1.9 \mathrm{E}-17$ & \pm & $9.8 \mathrm{E}-18$ & 1.9E-09 & \pm & $6.6 \mathrm{E}-10$ \\
\hline PFDS & & - & $3.1 \mathrm{E}-18$ & \pm & $1.0 \mathrm{E}-18$ & $5.6 \mathrm{E}-10$ & \pm & $0.0 \mathrm{E}+00$ \\
\hline PFOSA & $1.3 \mathrm{E}-15$ & $\pm \quad 1.4 \mathrm{E}-15$ & $1.0 \mathrm{E}-17$ & \pm & $6.2 \mathrm{E}-18$ & & - & \\
\hline
\end{tabular}
of air vapor $(\mathrm{n}=8)$, air particle $(\mathrm{n}=8)$, and rainwater $(\mathrm{n}=$ 3). Perfluoroheptanoic acids (PFHpA), perfluorononanoic acids (PFNA), perfluorodecanoic acids (PFDA) were detected above LOQ in all samples except for only one air particle sample, two air particle samples, and one rainwater sample, respectively. More highly fluorinated PFCAs, perfluoroundecanoic acid (PFUnDA) and perfluorododecanoic acid (PFDoDA), were less frequently detected. Particularly, air particle samples did not contain any detectable

Table 1. Concentrations of PFAAs Measured in Atmospheric Compartments

PFAS concentration include neutral and ionic species. Values < LOQ was treated to 'zero'. 
level of PFUnDA and contained PFDoDA above LOQ in only two samples. This may be attributable to rare occurrence of the highly fluorinated compounds in atmosphere. Otherwise, a relatively high particle-phase concentration would have been observed considering their relatively high octanol-air partition coefficients $\left(\mathrm{K}_{\mathrm{OA}}\right)$ compared with C7-C10 PFCAs.

Of four PFSAs, perfluorooctanesulfonic acid (PFOS) was also predominantly found in three atmospheric phases. The other PFSAs were not at all detected at least one of three phases; that is, perfluorohexanesulfonic acid (PFHS) in air particles and rainwater, perflorodecanesulfonic acid (PFDS) in air vapors, and perfluorooctane sulfonamide (PFOSA) in rainwaters were not detected. Thus, it was not allowed to calculate their $\mathrm{D}_{\mathrm{AW}}$ values and to predict their $\mathrm{pK}_{\mathrm{a}}$ for the three PFSAs.

\subsection{Estimation of $p K_{a}$ from Observed $D_{A W}$}

As mentioned earlier, the partitioning of PFAAs among atmospheric compartments strongly depends on their $\mathrm{pK}_{\mathrm{a}}$ and $\mathrm{K}_{\mathrm{AW}}$ and solution $\mathrm{pH}$ (Eq. (1)-(8)). A pH of 4.5 was used for a typical rainwater and air water phase on the basis of the meteorological data measured at urban area including northeastern states of US and Canada [11, 27]. For $\mathrm{pK}_{\mathrm{a}}$, a number of values for PFAAs have been suggested so far, which were estimated theoretically [28, 29], calculated from computational approach using software COSMO-RS [30, 31] and SPARC [32], or measured from laboratory experiment [33-35]. The suggested $\mathrm{pK}_{\mathrm{a}}$ values ranged from -0.21 to 3.8 for PFOA and from -3.3 to 0.14 for PFOS (Table 2). Various two-phase partition coefficients including $\mathrm{K}_{\mathrm{AW}}, \mathrm{K}_{\mathrm{OW}}$, and $\mathrm{K}_{\mathrm{OA}}$ have been also estimated from molecular structure (i.e., quantitative structure-activity relationships) using a variety of tools such as U.S. EPA's EPI Suite, ClogP, SPARC, and COSMOtherm [36]. According to previous results (see the literature in Table 2), those QSAR-based models produced the partition coefficients that differed more than three orders of magnitude: for instance, $\log \mathrm{K}_{\mathrm{AW}}=-2.37$ (COSMOtherm) to 0.57 (EPI Suite) for PFOA and -2.40 (COSMOtherm) to -0.35 (EPI Suite) for PFOS. Recently, Kim et al. [37] who used molar volume as a molecular descriptor suggested $\mathrm{K}_{\mathrm{AW}}$ values greater than 10 times than the maximum values suggested by previous QSAR-based models (Table 2).

Such wide ranges of $\mathrm{pK}_{\mathrm{a}}$ and $\mathrm{K}_{\mathrm{AW}}(\sim 10,000$ times difference between minimum and maximum values) could be significant fac
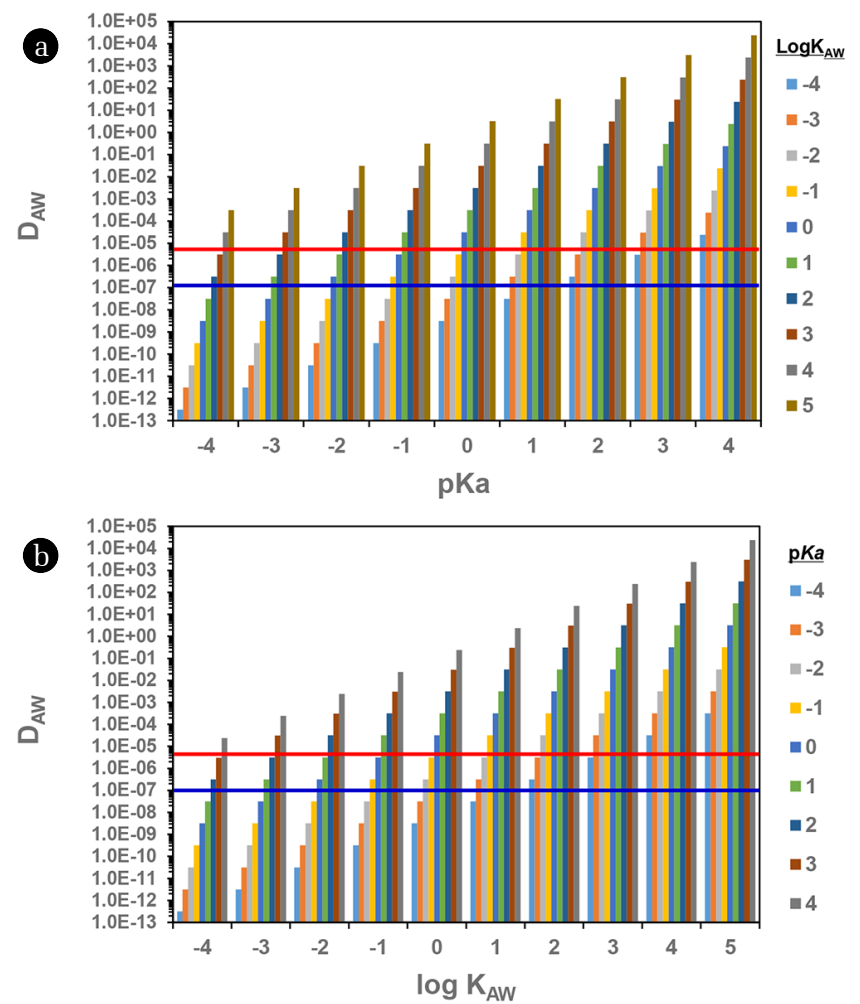

Fig. 1. Dependency of $D_{A W}$ on $\mathrm{pK}_{\mathrm{a}}$ and $\mathrm{K}_{\mathrm{AW}}$. The red and blue solid lines indicate the maximum and minimum value of observed $\mathrm{D}_{\mathrm{AW}}$ (see Table 3).

tors enlarging the uncertainty in the prediction of atmosphere-associated fate and transport including $\mathrm{D}_{\mathrm{AW}}, \mathrm{K}_{\mathrm{P}}$, dry/wet deposition, and long-range transport potential [12, 20-22]. To cover all PFAAs, we tested the sensitivity of $D_{\mathrm{AW}}$ with varying $\mathrm{pK}_{\mathrm{a}}(-4$ to 4$)$ and $\mathrm{K}_{\mathrm{AW}}\left(10^{-4}\right.$ to $\left.10^{5}\right)$ suggested (Fig. 1). At a given $\mathrm{pK}_{\mathrm{a}}$, the $\mathrm{D}_{\mathrm{AW}}$ value increases proportionally to $1: 1$ as $\mathrm{K}_{\mathrm{AW}}$ value increase. The suggested $\mathrm{K}_{\mathrm{AW}}$ range (log $\mathrm{K}_{\mathrm{AW}}=-2.37$ to 2.57 for PFOA and -2.4 to 3.29 for PFOS) produced the differences of $10^{4}$ and $10^{5}$ for $D_{A W}$, respectively. Similarly, $D_{A W}$ value at a given $\mathrm{K}_{\mathrm{AW}}$ increased in proportion to the increment of $\mathrm{pK}_{\mathrm{a}}$; that is, the $\mathrm{pK}_{\mathrm{a}}$ ranging from -4 to 4 yielded the variation of

Table 2. Physicochemical Properties for Fate of PFAAs Recommended in Literature

\begin{tabular}{|c|c|c|c|c|c|c|c|c|c|c|c|c|}
\hline \multirow[b]{2}{*}{ PFASs } & \multicolumn{2}{|r|}{ pKa } & \multicolumn{4}{|c|}{ Log KAW } & \multicolumn{4}{|c|}{ Log KOW } & \multicolumn{2}{|c|}{ Log KOC } \\
\hline & value & refs. & $\begin{array}{c}\text { COSMO- } \\
\text { therm }\end{array}$ & Ref. & QSAR & Ref. & $\begin{array}{c}\text { COSMO- } \\
\text { therm }\end{array}$ & Ref. & QSAR & refs. & $\begin{array}{l}\text { Sorption } \\
\text { test }\end{array}$ & refs. \\
\hline PFHpA & $-0.2-3.8$ & {$[11,28,29,43-45]$} & -2.66 & {$[36]$} & 2 & {$[37]$} & 3.82 & {$[36]$} & 1.19 & {$[37]$} & 2.1 & {$[47]$} \\
\hline PFOA & $-0.21-3.8$ & {$[11,28,29,43-45]$} & -2.37 & {$[36]$} & 2.57 & [37] & 4.3 & {$[36]$} & 1.79 & [37] & 2.11 & [48] \\
\hline PFNA & $-0.21-2.575$ & {$[11,28,29,43]$} & -2.03 & {$[36]$} & 3.14 & {$[37]$} & 4.84 & {$[36]$} & 2.4 & {$[37]$} & 2.5 & [48] \\
\hline PFDA & $-0.42-2.606$ & {$[11,28,29,43]$} & -1.79 & {$[36]$} & 3.7 & {$[37]$} & 5.3 & {$[36]$} & 3 & {$[37]$} & 2.92 & {$[48]$} \\
\hline PFUnDA & $-0.39-3.128$ & {$[11,28,29,43]$} & -1.52 & {$[36]$} & 4.18 & [37] & 5.76 & [36] & 3.51 & {$[37]$} & 3.47 & [48] \\
\hline PFDoDA & $-0.87-3.2$ & {$[11,28,29]$} & -0.58 & {$[46]$} & 4.84 & [37] & 6.41 & [36] & 4.21 & {$[37]$} & 4.7 & {$[47]$} \\
\hline PFOS & $-3.3-0.14$ & {$[11,45]$} & -2.4 & {$[36]$} & 3.29 & [37] & 5.25 & [36] & 2.56 & [37] & 2.68 & [48] \\
\hline
\end{tabular}


Table 3. Estimated pKa from Observed $D_{A W}$ of PFAAs between Air Vapor and Rainwater

\begin{tabular}{|c|c|c|c|c|c|c|}
\hline & \multicolumn{4}{|c|}{ Measured $D_{A W}$} & \multicolumn{2}{|c|}{ Estimated pKa } \\
\hline & Median & Average & Min & Max & This study & SPARC \\
\hline PFHpA & $4.2 \mathrm{E}-07$ & $3.8 \mathrm{E}-07$ & $1.3 \mathrm{E}-07$ & 8.4E-07 & 0.75 & -0.20 \\
\hline PFOA & $1.1 \mathrm{E}-06$ & $1.2 \mathrm{E}-06$ & $6.3 \mathrm{E}-07$ & 3.0E-06 & 0.96 & -0.21 \\
\hline PFNA & $1.1 \mathrm{E}-07$ & $1.4 \mathrm{E}-07$ & 7.9E-08 & $5.0 \mathrm{E}-07$ & -0.31 & -0.21 \\
\hline PFDA & 4.9E-07 & 5.6E-07 & 2.1E-07 & $1.4 \mathrm{E}-06$ & 0.04 & -0.22 \\
\hline PFUnDA & 2.7E-07 & $2.6 \mathrm{E}-07$ & $1.9 \mathrm{E}-07$ & 3.9E-07 & -0.55 & -0.22 \\
\hline PFDoDA & 4.7E-07 & $4.8 \mathrm{E}-07$ & $2.5 \mathrm{E}-07$ & 7.5E-07 & -1.24 & -0.22 \\
\hline PFOS & $1.5 \mathrm{E}-06$ & $1.8 \mathrm{E}-06$ & $6.3 \mathrm{E}-07$ & $8.4 \mathrm{E}-06$ & 1.16 & 0.14 \\
\hline
\end{tabular}

${ }^{\mathrm{a}}$ pKa estimated using SPARC (requoted from [11]).

eight orders of magnitude in $\mathrm{D}_{\mathrm{AW}}$ value. This implied again that the use of the more accurate values for $\mathrm{pK}_{\mathrm{a}}, \mathrm{pH}$ and $\mathrm{K}_{\mathrm{AW}}$ could be very important.

In the present study, we induced more reasonable values for $\mathrm{K}_{\mathrm{AW}}$ and $\mathrm{pK}_{\mathrm{a}}$ from $\mathrm{D}_{\mathrm{AW}}$ values which were calculated from PFAA concentrations measured in air vapor and rainwater. In calculating $\mathrm{D}_{\mathrm{AW}}\left(=C_{\text {air vapor }} / C_{\text {rainwater }}\right)$, it was assumed that the solely neutral species in air vapor phase and both neutral and ionic species in rainwater were present because the ionic species are nonvolatile: for example, log $\mathrm{K}_{\mathrm{AW}}$ of PFOA is -2.37 for neutral species (at suggested minimum value) versus -6.5 for ionic species [38]. The measured $\mathrm{D}_{\mathrm{AW}}$ values in this study ranged from $7.9 \times 10^{-8}$ to $8.4 \times 10^{-6}$ as for all investigated PFAAs (Table 3). When based on measured $D_{A W}$, thus $\log K_{A W}$ values should be within -4.0 to 0 for PFOA and -2 to 2 for PFOS as for their suggested $\mathrm{pK}_{\mathrm{a}}$ ranges. This indicated that at least the maximum values of $K_{A W}$ which were suggested by Kim et al. [37] would be not supported by our measurement. Two laboratory studies reported the $\mathrm{K}_{\mathrm{Aw}}$ values of 0.001 [39] and 0.004-0.007 [40], which were a good agreement with COSMOtherm-modeled data within less than an order of magnitude. So, the COSMOtherm-modeled values [36] were used for $\mathrm{K}_{\mathrm{Aw}}$ values of individual PFAAs in this study in order to maintain systematic consistency among the estimates of $\mathrm{K}_{\mathrm{Aw}}$. As the next step, we adjusted $\mathrm{pK}_{\mathrm{a}}$ values (at COSMOtherm-based $\mathrm{K}_{\mathrm{AW}}$ and $\mathrm{pH}=4.5$ ) to produce the best fitting (within $\pm 1 \%$ ) to the measured $\mathrm{D}_{\mathrm{AW}}$ (Table 3 ). The estimated $\mathrm{pK}_{\mathrm{a}}$ values in this study were close to the minimum values of previously suggested values except for PFOS which was greater than the suggested maximum value but were slightly higher than the estimates of SPARC.

Under the typical atmospheric condition (relative humidity = $50 \%$ and TSP $=60 \mu \mathrm{g} / \mathrm{m}^{3}$ ), the combination of the adjusted $\mathrm{pK}_{\mathrm{a}}$ values and the minimum $\mathrm{K}_{\mathrm{AW}}$ values suggested in literature predicted the $25 \%$ and $75 \%$ of PFOA and $33 \%$ and $67 \%$ of PFOS in air vapor and water phase, respectively. On the other hand, the use of the maximum value of suggested $\mathrm{K}_{\mathrm{AW} S}$ yielded the presence of almost $100 \%$ of PFOA and PFOS in air vapor phase. Similarly, the major phase of PFAA might significantly change within the suggested $\mathrm{pK}_{\mathrm{a}}$ range of -0.21 to 3.8 for PFOA and -3.3 to -0.14 for PFOS. For instance, it was predicted under the same typical condition with their adjusted $\mathrm{K}_{\mathrm{AW}} \mathrm{S}$ that the majority of atmospheric
PFOA and PFOS might exist in water phase when their minimum $\mathrm{pK}_{\mathrm{a}}$ values were applied while $99 \%$ of PFOA and $4.5 \%$ of PFOS in atmosphere might exist in air vapor phase when their maximum $\mathrm{pK}_{\mathrm{a}}$ values were used. Again, this indicated that use of inappropriate values for $\mathrm{pK}_{\mathrm{a}}$ and $\mathrm{K}_{\mathrm{AW}}$ would cause significant errors in prediction of partitioning among three phases and related fate and transport.

\subsection{Estimation of $K_{P}$ from Measured $K_{P}{ }^{\prime}$}

The $K_{P}^{\prime}$ was calculated using Eq. (3) from TSP-normalized total concentrations (a sum of neutral and ionic species) measured from aerosol and the concentration measured from air vapor phase (i.e., gaseous concentration of neutral species). The $\log K_{P}^{\prime}$ values measured in this study, ranging from $-2.27 \pm 0.26$ for PFOS to -1.65 \pm 0.47 for PFDoDA, were in very good agreement with $\log K_{P}^{\prime}$ values measured at a semi-urban location in Toronto, Canada [11] and at Lake Chaohu, China [13] (Table 4). It is particularly noticeable that the $\log K_{P}^{\prime}$ values we obtained most closely matched the values measured by annular diffusion denuder sampler used to avoid the sampling artifacts [11].

According to Eq. (4) and (8-1), the $K_{P}$ can be induced by multiplying $K_{P}^{\prime}$ and the fraction of neutral species on air particle to all species in aerosol ( $\left.\alpha_{\text {neutral on particle }}{ }^{\prime}\right)$. Our $\log K_{P}$ values ranged from $-8.28 \pm 0.27$ (for PFNA) to $-6.66 \pm 0.23$ (for PFOS). Contrary to $K_{P}^{\prime}$, the $K_{P}$ values showed the differences by an order of magnitude between different studies (Table 4). Unfortunately, Ahrens et al. [11] used the fraction of neutral species in water phase to all species in water phase instead of $\alpha_{\text {neutral on particle }}$. So, the difference between measured $K_{P}$ values may originate from the equation error. Use of different $\mathrm{pK}_{\mathrm{a}}$ values, for which SPARC-modeled value was used in in Ahrens et al. [11], can be another possible cause of $K_{P}$ difference.

\subsection{Dependency of Atmospheric Fate on $\mathrm{pH}$ and Relative Humidity}

A $\mathrm{pH}$ of 4.5, a typical value measured at urban area, was used in this study. Acid rain monitoring showed the variation of $\mathrm{pH}$ of 3.2-5.4 in the study area [27, 41]. Rain $\mathrm{pH}$ can be changed by acid-causing gases (ACGs) like $\mathrm{SO}_{2}, \mathrm{NO}_{\mathrm{x}}$, and $\mathrm{CO}_{2}$ as well as 
Table 4. Measured Gas-particle Partition Coefficients (Log $K_{P}^{\prime}$ versus Log $K_{p}$ )

\begin{tabular}{|c|c|c|c|c|c|c|c|c|c|c|c|}
\hline \multirow[b]{3}{*}{ PFHpA } & \multicolumn{5}{|c|}{$\log K_{P}^{\prime}\left(m^{3} / g\right)$} & \multicolumn{6}{|c|}{$\log K_{P}\left(m^{3} / g\right)$} \\
\hline & \multicolumn{3}{|c|}{ This study } & \multirow{2}{*}{$\frac{[11]^{\mathrm{a}}}{-}$} & \multirow{2}{*}{$\frac{{ }^{[13]^{\mathrm{a}}}}{-1.67}$} & \multicolumn{3}{|c|}{ This study } & \multicolumn{3}{|c|}{$[11]^{\mathrm{a}}$} \\
\hline & -1.66 & \pm & 0.33 & & & -7.88 & \pm & $0.36(0.75)^{b}$ & & - & \\
\hline PFOA & -2.05 & \pm & 0.26 & -2.43 & -1.34 & -7.59 & \pm & $0.26(0.96)$ & -7.14 & \pm & $0.3(-0.21)$ \\
\hline PFNA & -2.00 & \pm & 0.28 & -2.31 & -1.89 & -8.28 & \pm & $0.27(-0.31)$ & -7.02 & \pm & $0.5(-0.21)$ \\
\hline PFDA & -2.17 & \pm & 0.40 & -2.26 & -1.58 & -7.63 & \pm & $0.32(0.04)$ & -7.08 & \pm & $0.6(-0.22)$ \\
\hline PFUnDA & & - & & -1.59 & -1.64 & & & & -6.31 & \pm & $0.3(-0.22)$ \\
\hline PFDoDA & -1.65 & \pm & 0.47 & -1.75 & -1.49 & -7.40 & \pm & $0.29(-0.55)$ & -6.53 & \pm & $0.6(-0.22)$ \\
\hline PFBS & & - & & -2.30 & -2.52 & & & & -1.90 & \pm & $0.4(0.14)$ \\
\hline PFHS & & - & & - & -1.59 & & & & & - & \\
\hline PFOS & -2.27 & \pm & 0.26 & -1.42 & -1.91 & -6.66 & \pm & $0.23(1.16)$ & -5.78 & \pm & $0.3(0.14)$ \\
\hline
\end{tabular}

${ }^{a}$ cited literature; bvalues in parentheses indicate $\mathrm{pK}_{\mathrm{a}}$ used.

by particulate matter (PM), causing large variation as shown evidently in observed $\mathrm{pH}$ values (from $<4.5$ to 7.5 ) [42].

Fig. 2 shows the pH-dependence of the occurrence of PFAAs in each of three phases. Under the meteorological condition of $\mathrm{rH}=50 \%$ and $\mathrm{TSP}=60 \mu \mathrm{g} / \mathrm{m}^{3}$, the $\mathrm{pH}=4.5$ yielded that $>90 \%$ of individual PFCAs (90\% of PFOA) and $86 \%$ of PFOS might exist in water phase, $0.2-10 \%$ of PFCAs $(10 \%$ of PFOA) and $14 \%$ of PFOS in vapor phase, and $<1 \%$ of PFCAs and PFOS in particle phase. The water phase fraction of PFAAs, mostly ionic species, can increase with increment of $\mathrm{pH}$ and then reach more than $99 \%$
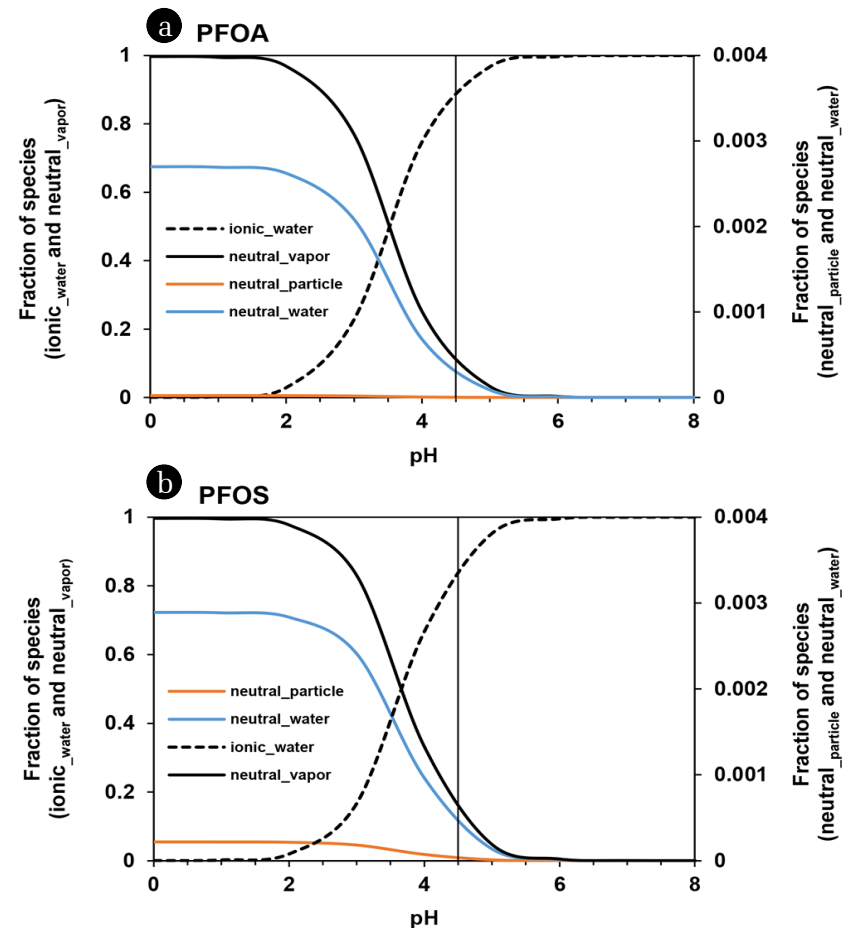

Fig. 2. Fraction of neutral and ionic species of PFOA (a) and PFOS (b) adsorbed on air particle, in air vapor, and in water phase with $\mathrm{pH}$ values. A vertical solid line indicates $\mathrm{pH}=4.5$. above $\mathrm{pH}=6.0$. It was predicted that drastic change in the fraction of PFAAs could occur in the lower $\mathrm{pH}$ condition. At $\mathrm{pH}=\sim 3.5$ and $\sim 3.7$, a half of PFOA and PFOS may exist in vapor phase and another half in water phase. More acidified condition (i.e., more severe atmospheric pollution by ACGs) can cause the prevalent vapor phase $(>99 \%$ ) of $\mathrm{PFOA}$ at $\mathrm{pH}=1.3$ and of PFOS at $\mathrm{pH}$ $=$ 1.5. Consequently, PFAAs in ACG-polluted air of urban/industrial area, i.e., at low $\mathrm{pH}$ air condition, can be moved via gaseous diffusion and wind-driven gaseous transport to other region and then can reside more shortly in the environmental system of the emitted region. On the other hand, PFAAs in rural area, of which air may be less polluted by ACGs and then be at relatively high $\mathrm{pH}$ (mostly, $>$-5.4), can reside much longer in the environment of the domain system because the majority of individual PFAAs may exist in water phase (e.g., clouds and fogs) and can fall down via deposition of atmospheric water (e.g., rainfall and snow). Moreover it is difficult for deposited PFAAs to be evaporated considering the higher $\mathrm{pH}$ condition of freshwater ( $\mathrm{pH}=\sim 7.5$ ) where non-volatile ionic species may exist exclusively. In short, PFAAs can distribute ubiquitously and relatively uniformly from urban to rural regions by their $\mathrm{pH}$-dependent atmospheric fate.

The volume of atmospheric water is extremely variable in time and space with the meteorological condition. Dependency of phase fractions of each species on relative humidity was presented in Fig. 3. Increase of relative humidity is inevitably associated with increasing occurrence of PFAA in water phase. In $>40 \%$ of $\mathrm{rH}$, the most of PFOA and PFOS (i.e., > 80\%) may exist in atmospheric water phase. However, the more than 1\% of PFAAs (e.g., 5\% of PFOA and $7 \%$ of PFOS) can be still present as a neutral species in vapor phase even in water-saturated condition such as fog. Vapor phase fraction of PFOA and PFOS may be more abundant below $5 \%$ and $8 \%$ of $\mathrm{rH}$, respectively. More fluorinated PFCAs (> C10 PFCAs) were predicted to exist mostly in a vapor phase $(>50 \%)$ under the perfectly dried condition $(<2 \%$ of $\mathrm{rH}$ ). Air particle-phase of PFAA accounted for $<0.1 \%$ in any cases with $\mathrm{rH}$ variation and exceeded $1 \%$ only for an extreme condition such as TSP $=5,000$ $\mu \mathrm{g} / \mathrm{m}^{3}$ and $\mathrm{rH}=0 \%$. This indicates that dry deposition and rain scavenging of particle-adsorbed PFAAs are likely negligible. 

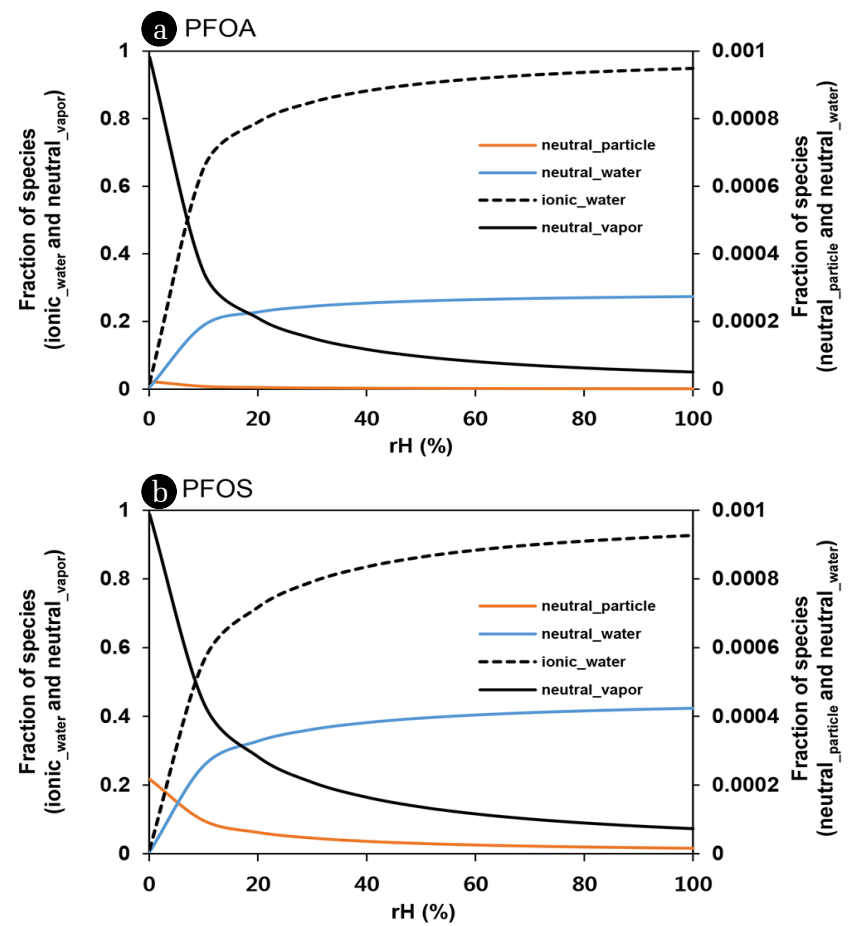

Fig. 3. Fraction of neutral and ionic species of PFOA (a) and PFOS (b) adsorbed on air particle, in air vapor, and in water phase with relative humidity.

\section{Conclusions}

Environmental fate of ionizable organic pollutants such PFAAs strongly depends on their water-phase associated physicochemical properties such as $\mathrm{pK}_{\mathrm{a}}, \mathrm{pH}$, and $\mathrm{K}_{\mathrm{Aw}}$. So far a wide range of values for the parameters $(\sim 10,000$ times difference between minimum and maximum values of $\mathrm{pK}_{\mathrm{a}}$ and $\mathrm{K}_{\mathrm{AW}}$ ) have been suggested, could be significant factors enlarging the uncertainty in the prediction of atmosphere-associated fate and transport including $\mathrm{D}_{\mathrm{AW}}, \mathrm{K}_{\mathrm{P}}$, dry/wet deposition, and long-range transport potential. The result of our sensitivity analysis showed that the major phase of PFAAs present in atmosphere could significantly change within the range of suggested values for the parameters, indicating that the accurate values for the parameters are essential in assessing atmospheric and sequential fate. So, we induced the $\mathrm{pK}_{\mathrm{a}}$ and $\mathrm{K}_{\mathrm{AW}}$ values by adjusting to in situ measurements of $\mathrm{D}_{\mathrm{AW}}$ between air vapor phase and rainwater, and estimated $K_{P}$ of PFAAs using in situ measured gas-aerosol partition coefficient and obtained parameter values.

Our study is expected to have some implications in prediction of the environmental redistribution of other ionizable organic compounds since the atmospheric three-phase partitioning of ionizable organic pollutant is strongly associated with their redistribution among environmental compartments via volatilization, dry/wet deposition, rainfall scavenging, advection, and sorption to terrestrial surface. The redistribution of ionizable organic pollutants through atmospheric fate can be of particular importance in the coastal region where those pollutant can move backward, i.e., from the sea to the land. Our study will be helpful to understand such a fate of ionizable organic pollutants.

\section{Acknowledgments}

This work was supported by Incheon National University (International Cooperative) Research Grant in 2014.

\section{References}

1. Wang T, Wang Y, Liao C, Cai Y, Jiang G. Perspectives on the inclusion of perfluorooctane sulfonate into the Stockholm Convention on persistent organic pollutants. Environ. Sci. Technol. 2009;43:5171-5175.

2. Gouin T, Wania F. Time trends of Arctic contamination in relation to emission history and chemical persistence and partitioning properties. Environ. Sci. Technol. 2007;41:5986-5992.

3. Wang Z, Xie Z, Möller A, Mi W, Wolschke H, Ebinghaus R. Atmospheric concentrations and gas/particle partitioning of neutral poly- and perfluroalkyl substances in Northern German coast. Atmos. Environ. 2014;95:207-213.

4. Xie Z, Wang Z, Mi W, Möller A, Wolschke H, Ebinghaus R. Neutral poly-/perfluoroalkyl substances in air and snow from the Arctic. Sci. Rep. 2015;5:8912.

5. Buck RC, Franklin J, Berger U, et al. Perfluoroalkyl and polyfluoroalkyl substances in the environment: Terminology, classification, and origins. Int. Environ. Assess. Manage. 2011;7:513-541.

6. Ellis DA, Martin JW, De Silva AO, et al. Degradation of fluorotelomer alcohols: A likely atmospheric source of perfluorinated carboxylic acids. Environ. Sci. Technol. 2004;38:3316-3321.

7. Wallington TJ, Hurley MD, Xia J, et al. Formation of $\mathrm{C} 7 \mathrm{~F} 15 \mathrm{COOH}$ (PFOA) and other perfluorocarboxylic acids during the atmospheric oxidation of 8:2 fluorotelomer alcohol. Environ. Sci. Technol. 2006;40:924-930.

8. Kim S-K, Kannan K. Perfluorinated acids in air, rain, snow, surface runoff, and lakes: Relative importance of pathways to contamination of urban lakes. Environ. Sci. Technol. 2007;41:8328-8334.

9. Yarwood G, Kemball-Cook S, Keinath M, et al. High-resolution atmospheric modeling of fluorotelomer alcohols and perfluorocarboxylic acids in the North American troposphere. Environ. Sci. Technol. 2007;41:5756-5762.

10. Kim S-K, Li D-H, Shoeib M, Zoh K-D. Contribution of diffuse inputs to the aqueous mass load of perfluoroalkyl acids in river and stream catchments in Korea. Sci. Total Environ. 2014;470471:1430-1440.

11. Ahrens L, Harner T, Shoeib M, Lane DA, Murphy JG. Improved characterization of gas-particle partitioning for per- and polyfluoroalkyl substances in the atmosphere using annular diffusion denuder samplers. Environ. Sci. Technol. 2012;46:7199-7206.

12. Vierke L, Ahrens L, Shoeib M, et al. In situ air-water and particle-water partitioning of perfluorocarboxylic acids, perfluorosulfonic acids and perfluorooctyl sulfonamide at a wastewater treatment plant. Chemosphere 2013;92:941-948.

13. Liu W, He W, Wu J, Wu W, Xu F. Distribution, partitioning and inhalation exposure of perfluoroalkyl acids (PFAAs) in 
urban and rural air near Lake Chaohu, China. Environ. Pollut. 2018;243:13-151.

14. McMurdo C, Ellis D, Webster E, Butler J, Christensen RD, Reid LK. Aerosol enrichment of the surfactant PFO and mediation of the water-air transport of gaseous PFOA. Environ. Sci. Technol. 2008;42:3969-3974.

15. Ju X, Jin Y, Sakaki K, Saito N. Perfluorinated surfactants in surface, subsurface water and microlayer from Dalian coastal waters in China. Environ. Sci. Technol. 2009;42:3538-3542.

16. Cho Y-K, Kim M-O, Kim B-C. Sea fog around the Korean peninsula. J. Appl. Meteorol. 2000;39:2473-2479.

17. Wang T, Wang P, Meng J, et al. A review of sources, multimedia distribution and health risks of perfluoroalkyl acids (PFAAs) in China. Chemosphere 2015;129:87-99.

18. Tian Z, Kim S-K, Shoeib M, Oh J-E, Park J-E. Human exposure to per- and polyfluoroalkyl substances (PFASs) via house dust in Korea: Implication to exposure pathway. Sci. Total Environ. 2016;553:266-275.

19. Schwarzenbach RP, Gschwend PM, Imboden DM. Environmental organic chemistry. 2nd ed. Hoboken: John Wiley \& Sons; 2002.

20. Qureshi A, MacLeod M, Hungerbühler K. Modeling aerosol suspension soils and oceans as sources of micropollutants to air. Chemosphere 2009;77:495-500.

21. Franco A, Haushild M, Jolliet O, Trapp S. Atmospheric fate of non-volatile and ionizable compounds. Chemosphere 2011;85:1353-1359.

22. Gomis MI, Wang Z, Scheringer M, Cousins IT. A modeling assessment of the physicochemical properties and environmental fate of emerging and novel per- and polyfluoroalkyl substances. Sci. Total Environ. 2015;505:981-991.

23. Pankow JF. Review and comparative analysis of the theories on partitioning between the gas and aerosol particulate phases in the atmosphere. Atmos. Environ. 1987;21:2275-2283.

24. Masiol M, Hopke PK, Felton HD, et al. Analysis of major air pollutants and submicron particles in New York City and Long Island. Atmos. Environ. 2017;148:203-214.

25. Squizzato S, Masiol M, Rich DQ, Hopke PK. A long-term source apportionment of $\mathrm{PM}_{2.5}$ in New York State during 2005-2016. Atmos. Environ. 2018;192:35-47.

26. Mackay D. Multimedia environmental models - The fugacity approach. 2nd ed. Boca Raton (FL): Taylor \& Francis; 2001.

27. Jenkins J, Roy K, Driscoll C, Buerkett C. Acid rain in the Adirondacks: An environmental history. New York: Cornell Univ. Press; 2007.

28. Rayne S, Forest K. Perfluoroalkyl sulfonic and carboxylic acids: A critical review of physicochemical properties, levels and patterns in waters and wastewaters, and treatment methods. J. Environ. Sci. Health A 2009;44:1145-1199.

29. Rayne S, Forest K, Friesen KJ. Computational approaches may underestimate $\mathrm{pK}_{\mathrm{a}}$ values of longer-chain perfluorinated carboxylic acids: Implication for assessing environmental and biological effects. J. Environ. Sci. Health A 2009b;44:317-326.

30. Klamt A, Eckert F, Diedenhofen M, Beck ME. First principles calculations of aqueous $\mathrm{pK}_{\mathrm{a}}$ values for organic and inorganic acids using COSMO-RS reveal an inconsistency in the slope of the $\mathrm{pK}_{\mathrm{a}}$ scale. J. Phys. Chem. A 2003;107:9380-9386.

31. Eckert F, Klamt A. Accurate prediction of basicity in aqueous solution with COSMO-RS. J. Comput. Chem. 2006;27:11-19. 32. Hilal SH, Karickhoff SW, Carreira LAA. Rigorous test for SPARC's chemical reactivity models: Estimation of more than 4300 ionization $\mathrm{pK}_{\mathrm{a}} \mathrm{s}$. Quant. Struct.-Act. Relat. 1995;14:348-355.

33. Igarashi S, Yotsuyanagi T. Homogeneous liquid-liquid extraction by $\mathrm{pH}$ dependent phase separation with a fluorocarbon ionic surfactants and its application to the preconcentration of porphyrin compounds. Microchim. Acta 1992;106:37-44.

34. Moroi Y, Yano H, Shibata O, Yonemitsu T. Determination of acidity constants of perfluoroalkanoic acids. Bull. Chem. Soc. Jpn. 2001;74:667-672.

35. Burns D, Ellis DA, Li H, McMurdo CJ, Webster E. Experimental $\mathrm{p} K_{\mathrm{a}}$ determination for perfluorooctanoic acid (PFOA) and the potential impact of $\mathrm{p} K_{\mathrm{a}}$ concentration dependence on laboratory-measured partitioning phenomena and environmental modeling. Environ. Sci. Technol. 2008;42:9283-9288.

36. Arp HPH, Niederer C, Goss K-U. Predicting the partitioning behavior of various highly fluorinated compounds. Environ. Sci. Technol. 2006;40:7298-7304.

37. Kim M, Li LY, Grace JR, Ye C. Selecting reliable physicochemical properties of perfluoroalkyl and polyfluoroalkyl substances (PFASs) based on molecular descriptors. Environ. Pollut. 2015;196:462-472.

38. Wania FA. A global mass balance analysis of the source of perfluorocarboxylic acids in the Arctic Ocean. Environ. Sci. Technol. 2007;41:4529-4535.

39. Li H, Ellis DA, Mackay D. Measurement of low air-water partition coefficients of organic acids by evaporation from a water surface. J. Chem. Eng. Data 2007;52:1580-1584.

40. Kutsuna S, Hori H. Experimental determination of Henry's law constant of perfluorooctanoic acid (PFOA) at $298 \mathrm{~K}$ by means of an inert-gas stripping method with a helical plate. Atmos. Environ. 2008;42:8883-8892.

41. Khwaja HA, Husain L. Chemical characterization of acid precipitation in Albany, New York. Atmos. Environ. 1990;24:1869-1882.

42. Singh S, Elumalai SP, Pal AK. Rain pH estimation based on the particulate matter pollutants and wet deposition study. Sci. Total Environ. 2016;563-564:293-301.

43. Ding G, Peijnenburg WJGM. Physicochemical properties and aquatic toxicity of poly- and perfluorinated compounds. Crit. Rev. Environ. Sci. Technol. 2013;43:598-678.

44. Arp HPH, Goss K-U. Gas/particle partitioning behavior of perfluorocarboxylic acids with terrestrial aerosols. Environ. Sci. Technol. 2009;43:8542-8547.

45. Brooke D, Footitt A, Nwaogu TA. Environmental risk evaluation report: Perfluorooctanesulphonate (PFOS) [Internet]. Environmental Agency; c2004. Available from: http://www.environmentagency. gov.uk/commondata/105385/pfos_rer_sept04_864557.pdf.

46. Wang Z, MacLeod M, Cousins IT, Scheringer M, Hungerbuhler K. Using COSMOtherm to predict physicochemical properties of poly- and perfluorinated alkyl substances (PFASs). Environ. Chem. 2011;8:389-398.

47. Labadie P, Chevreuil M. Partitioning behavior of perfluorinated alkyl contaminants between water, sediment and fish in the Orge River (nearby Paris, France). Environ. Pollut. 2011;159:391-397.

48. Higgins CP, Luthy RG. Sorption of perfluorinated surfactants on sediments. Environ. Sci. Technol. 2006;40:7251-7256. 